\title{
Avaliação do desempenho de telhados verdes e reservatórios de lote no amortecimento de vazões de pico em uma bacia urbana
}

\section{Performance assessment of green roofs and rain barrels for reducing peak flows in an urban watershed}

\author{
Data de entrada: \\ 02/08/2019 \\ - Data de aprovação: \\ $19 / 08 / 2019$
}

Júlia Baptistella Machado Dutra' | Talita Fernanda das Graças Silva ${ }^{1 *}$

ORCID ID

Dutra JBM (iD) https://orcid.org/0000-0002-4420-5636
DOI: https://doi.org/10.36659/dae.2020.080

\section{Resumo}

Mudanças no uso do solo e impermeabilização das superfícies têm aumentado a ocorrência de inundações nas cidades brasileiras. Este trabalho investiga como telhados verdes e reservatórios de lote minimizam inundações urbanas ao reduzir o escoamento superficial e a vazão de pico. A bacia do córrego Engenho Nogueira (Belo Horizonte, MG) foi escolhida como estudo de caso. O Storm Water Management Model foi utilizado para simular três cenários: C0, situação atual; C100 e C50, implantando as técnicas, respectivamente, em 100\% e $50 \%$ das áreas potenciais. 0 escoamento superficial na bacia foi reduzido em até $22,3 \%$ devido ao bom desempenho dos telhados verdes, com escoamento superficial nulo e volumes drenados até $25,5 \%$ inferiores ao volume precipitado. Os reservatórios de lote apresentaram baixo desempenho devido ao volume insuficiente. A vazão de pico no exutório da bacia foi reduzida em no máximo 11,6\% (C100, chuva com tempo de retorno de 10 anos e duração de 10 minutos).

Palavras-chave: Low Impact Development. Técnicas compensatórias. SWMM. Drenagem urbana.

\section{Abstract}

Land use changes and increasing imperviousness have increased flood frequency in Brazilian cities. This paper investigates how green roofs and rain barrels minimize urban flooding by reducing surface runoff and peak flow. Engenho Nogueira stream watershed (Belo Horizonte, MG) was chosen as case study. Storm Water Management Model was used to simulate three scenarios: CO, the watershed's current situation; C100 and C50, considering green roofs and rain barrels in respectively $100 \%$ and $50 \%$ of the potential areas. Surface runoff volume in the watershed reduced at most $22.3 \%$ due to the good performance of green roofs, which presented zero runoff and maximum outflow volume $25.5 \%$ smaller than rainfall volume. Rain barrels did not perform well due to insufficient volume. Peak flow at the watershed outlet reduced by a maximum of $11.6 \%$ (C100, rainfall with 10 years return period and 10 minutes duration).

Keywords: Low Impact Development. Sustainable Urban Drainage. SWMM. Urban drainage.

\footnotetext{
${ }^{1}$ Universidade Federal de Minas Gerais - Belo Horizonte - Minas Gerais - Brasil.

* Autora correspondente: talita.silvaaehr.ufmg.br.
} 


\section{INTRODUÇÃO}

As inundações são fenômenos que ocorrem naturalmente a partir da variação sazonal de vazões nos cursos d'água. Entretanto, a partir da urbanização, as inundações passam a acontecer como consequência de dois principais processos: primeiramente, devido à ocupação inadequada das planícies naturais de inundação dos corpos d'água; em segundo lugar, pelo próprio processo de urbanização em si (TUCCl, 2018). Nesse último caso, os eventos de inundação derivam da impermeabilização do solo e do consequente aumento da velocidade e volume de escoamento superficial, além de ocorrerem devido a deficiências no sistema de drenagem.

Outro impacto trazido pelo processo de urbanização, muito semelhante às inundações, são os alagamentos. Eles são definidos como "a extrapolação da capacidade de escoamento de sistemas de drenagem urbana e consequente acúmulo de água em ruas, calçadas ou outras infraestruturas urbanas, em decorrência de precipitações intensas" (COBRADE, 2012).

As inundações e os alagamentos frequentemente acarretam perdas materiais e, por vezes, também de vidas humanas. Nesse sentido, ocorre uma pressão da população para que o poder público corrija problemas na drenagem urbana com soluções estruturais, como a canalização de novos rios e córregos ou a construção de bacias de detenção para amortecer e/ou retardar o escoamento superficial. Entretanto, mesmo com essas obras implementadas - e que são extremamente caras, especialmente em áreas já urbanizadas -, prejuízos financeiros, ambientais, estéticos e sanitários continuam ocorrendo, conforme explicitado por Lucas et. al. (2015).

Isto posto, torna-se necessário buscar medidas complementares para evitar ou minimizar a ocorrência de inundações urbanas, analisando a bacia hidrográfica como um todo e considerando soluções que atuem em conjunto, em vez de apenas pontualmente (ECKART, MCPHEE E BOLISETTI, 2017).

Algumas medidas que atendem a esses critérios são as chamadas técnicas compensatórias em drenagem urbana. Segundo ReCESA (2007), seu uso busca neutralizar ou minimizar os efeitos da urbanização sobre os processos hidrológicos, beneficiando a qualidade de vida e a preservação ambiental. Essas técnicas procuram evitar a transferência rápida para jusante dos excedentes de água gerados a partir de estruturas de armazenamento temporário (retenção) e infiltração (ROSA, 2017).

As técnicas compensatórias podem ser divididas em três grandes grupos: técnicas para controle na fonte, técnicas para controle no sistema viário e técnicas para controle a jusante. As técnicas para controle na fonte estão associadas à drenagem de pequenas áreas da bacia e são o objeto de estudo deste trabalho. Alguns exemplos são: valetas, trincheiras, poços de infiltração, células de bio-retenção, reservatórios domésticos de armazenamento da água da chuva (ou reservatórios de lote) e telhados verdes.

Assim, o presente artigo tem o objetivo de investigar, por meio de modelagem matemática, como as técnicas compensatórias de controle "na fonte", especificamente os telhados verdes e os reservatórios de lote, podem contribuir com a redução do escoamento superficial, a redução da vazão de pico e o aumento do tempo de pico em uma bacia urbana. Para isso, escolheu-se como estudo de caso a bacia do córrego Engenho Nogueira (Belo Horizonte - MG).

\section{METODOLOGIA}

\subsection{A bacia do Córrego Engenho Nogueira}

A bacia do Córrego Engenho Nogueira, inserida nas regionais Noroeste e Pampulha da cidade de Belo Horizonte, possui área total de $10,04 \mathrm{~km}^{2}$ e população de 45.513 habitantes (BELO HORI- 
ZONTE, 2016). Ela faz parte da bacia do Ribeirão Onça, que compõe a bacia do Rio das Velhas, afluente do rio São Francisco. A delimitação da área da bacia do Córrego Engenho Nogueira está apresentada na Fig. 1.

Essa bacia há anos vem sendo alvo de intervenções da Prefeitura Municipal de Belo Horizonte -
$\mathrm{PBH}$, em termos de saneamento básico e drenagem urbana. Uma dessas ações, realizada a partir do Programa de Recuperação Ambiental de Belo Horizonte - Drenurbs, iniciado em 2010 (BELO HORIZONTE, 2016), foi a construção de uma bacia de detenção de cheias, galeria e rede de drenagem pluvial na porção média da bacia.

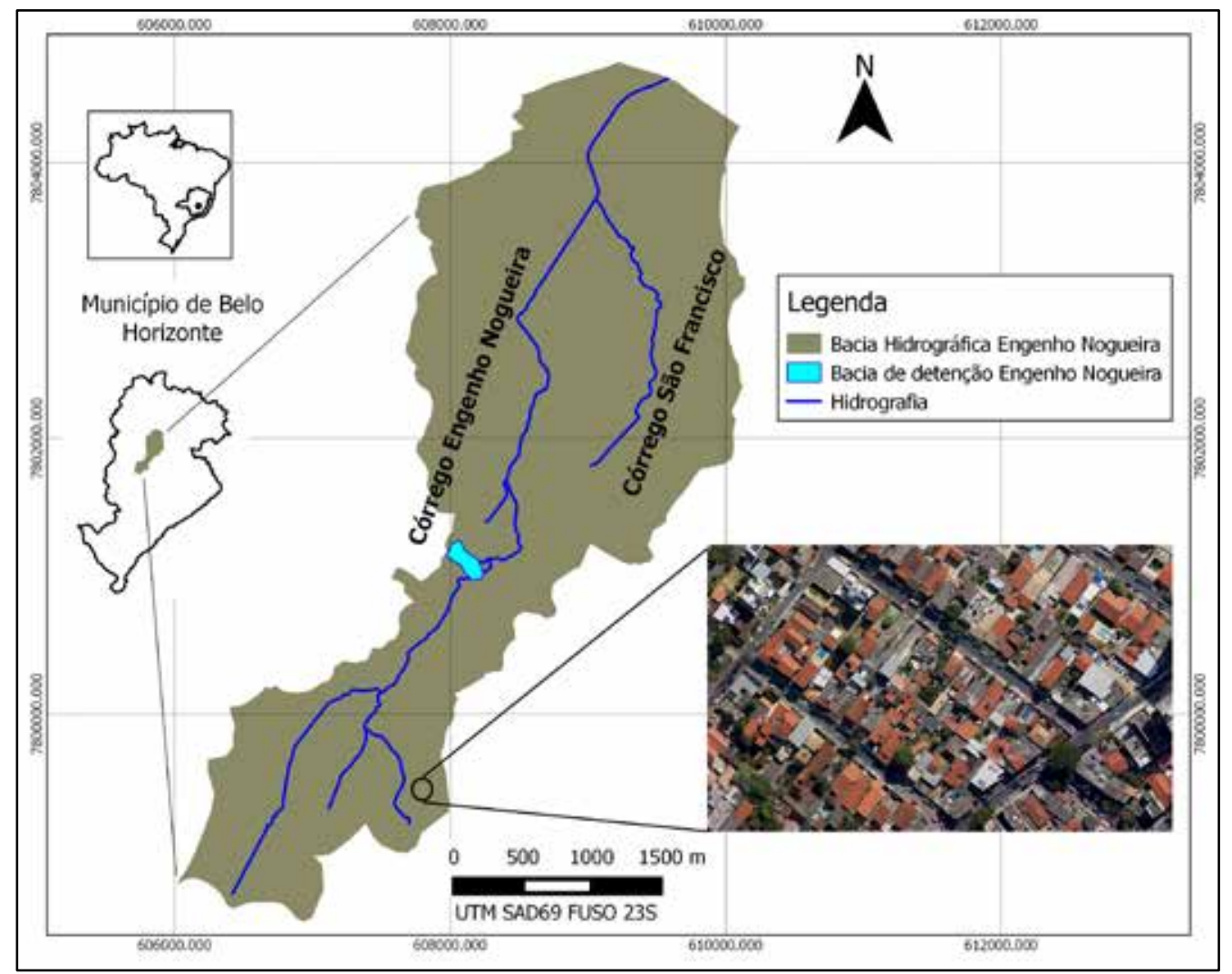

Figura 1 - Localização da bacia do córrego Engenho Nogueira.

\subsection{Técnicas compensatórias selecionadas para o estudo}

A análise de imagens de satélite da área de estudo, datadas de 15 de maio de 2018, por meio do software Google Earth Pro (versão 7.3.2.5776, Google), permitiu verificar que diversos lotes são ocupados por casas com telhados inclinados (teIhas cerâmicas), enquanto outros são ocupados por pequenos edifícios ou grandes galpões. Além disso, poucos lotes apresentam área de jardins. A Fig. 1 ilustra parte do bairro Alto Caiçara, perten- cente à porção de montante da bacia em estudo, evidenciando a prevalência de casas na região com telhados inclinados e praticamente sem jardim nos lotes, bem como alguns edifícios.

Essas características favorecem a implantação dos reservatórios de lote e telhados verdes, em detrimento de trincheiras ou poços de infiltração, por exemplo.

Os telhados verdes são um tipo de técnica compensatória que atua retardando o escoamento das 
águas pluviais, por meio da vegetação e da percolação da água em seu substrato (TASSI, 2002). Dessa forma, é possível reduzir o pico de vazão direcionada aos sistemas de drenagem urbana.

De acordo com Tomaz (2009), os telhados verdes geralmente são aplicados em inclinações até $5^{\circ}$, podendo chegar a $20^{\circ}$. Eles podem ser extensivos, com vegetação de menor porte e menor sobrecarga estrutural, ou intensivos, com espécies vegetais de maior porte e maior sobrecarga.

Já os reservatórios de lote não apresentam substrato vegetal e atuam a partir da retenção do escoamento das águas pluviais. Segundo Tassi (2002), esses reservatórios procuram restituir a capacidade de armazenamento natural perdida com a urbanização, amenizando o pico do hidrograma efluente do lote. Segundo a autora, um cuidado que se deve ter ao adotar essa técnica compensatória em uma bacia é simular e planejar corretamente durante a fase de projeto, para que o resultado não seja o inverso do esperado: o aumento do pico de vazão justamente pela chegada simultânea de diversos hidrogramas atrasados no exutório da bacia.

\subsection{0 modelo hidrológico e hidráulico}

Para a modelagem hidrológica e hidráulica da bacia do Córrego Engenho Nogueira utilizou-se o software Storm Water Management Model - SWMM, cuja função principal é simular o escoamento de águas de chuva em ambientes urbanos atentando-se para o dimensionamento do sistema de drenagem e para aspectos de qualidade da água (ROSSMAN, 2015). Foi escolhido por ser um software livre e de código aberto, bem documentado e referenciado na literatura internacional e nacional, com exemplos de aplicação no Brasil (SIQUUEIRA, MOURA, SILVA, 2019; SILVA et al., 2016; SILVA et al., 2019). Além disso, ele apresenta um menu específico para a inserção de técnicas compensatórias na bacia hidrográfica.

O presente trabalho foi realizado a partir de um modelo da bacia do Engenho Nogueira já construído e calibrado, utilizado em estudo anterior. No SWMM, a bacia hidrográfica é dividida em sub-bacias. O usuário é responsável por fazer essa divisão, delimitando sub-bacias com características similares de declividade, uso, ocupação e tipo de solo. A divisão adotada no estudo está apresentada na Fig. 2.

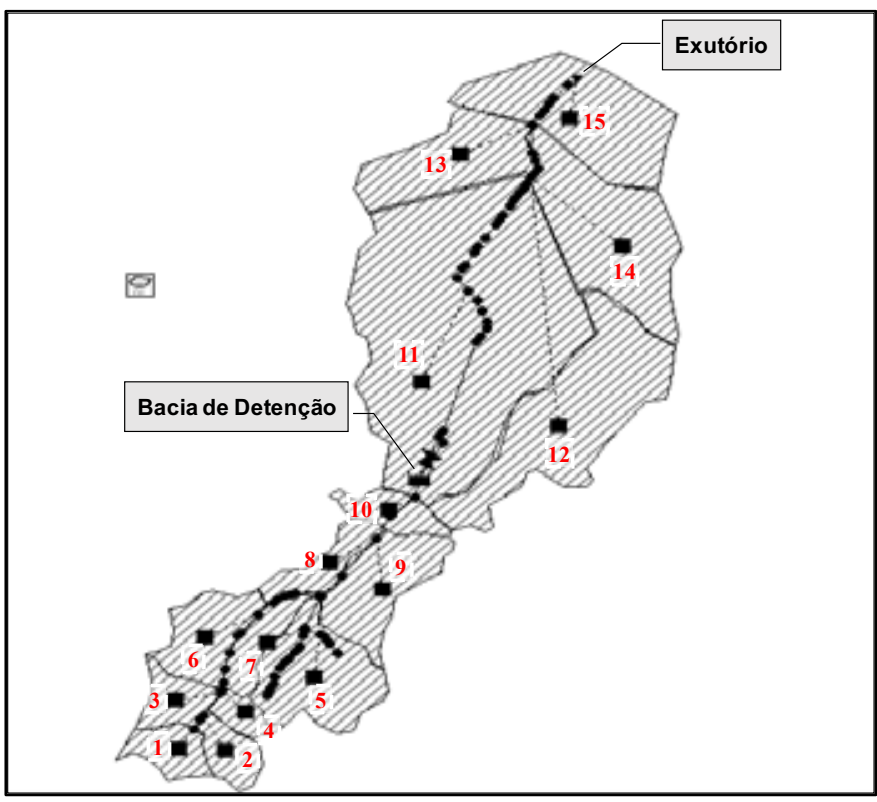

Figura 2 - Divisão da bacia do Engenho Nogueira em sub-bacias, modeladas para o software SWMM. 
No modelo aqui empregado, o cálculo da chuva efetiva em cada sub-bacia foi realizado por meio do método do Número da Curva - Curve Number (CN) do Soil Conservation Service, atual Natural Resources Conservation Services (NRCS, 2004). Em relação ao escoamento na superfície da subbacia, o SWMM considera um modelo de reservatório não linear e a propagação do escoamento nos condutos é realizada por meio das equações de Saint-Venant 1-D (ROSSMAN, 2015).

As técnicas compensatórias modeladas no SWMM incluem células de bio-retenção, jardins de chuva, telhados verdes, trincheiras de infiltração, pavimentos permeáveis, reservatórios de lote e valas vegetadas. Elas são constituídas por um conjunto de camadas sobrepostas verticalmente, as quais variam de acordo com a técnica. Os telhados verdes, por exemplo, são compostos por uma camada superficial, camada de solo e camada drenante. Os reservatórios de lote por sua vez, possuem apenas camada superficial e a camada drenante.

O escoamento superficial que chega até a camada superficial das técnicas pode (i) infiltrar por todas as camadas até o solo, (ii) infiltrar e ser direcionado para um dreno de fundo, (iii) infiltrar e evaporar ou, ainda, (iv) continuar como um escoamento superficial, quando as camadas não forem mais capazes de absorver o fluxo. A modelagem das técnicas ocorre a partir da solução da equação da continuidade, dada pela diferença entre as vazões de entrada e saída em cada camada, em um dado intervalo de tempo. Mais detalhes sobre a simulação dessas técnicas no SWMM podem ser encontrados em Rossman (2016).

\subsection{Simulação das técnicas compensatórias adotadas}

Uma vez escolhidas as técnicas compensatórias a serem inseridas em cada sub-bacia e simuladas no modelo do SWMM, foi necessário definir as propriedades de suas camadas. Para os telhados verdes, esses valores estão apresentados na Tabela 1 e, para os reservatórios de lote, na Tabela 2.

Para os telhados verdes foi adotado solo do tipo franco-arenoso, que apresenta alta permeabilidade devido à fração areia e é adequado ao desenvolvimento de espécies vegetais (ROSSMAN, 2015).

Os reservatórios de lote foram implantados em dois tamanhos: $1,08 \mathrm{~m}^{3}$ para lotes de até $360 \mathrm{~m}^{2}$ e 3,60 $\mathrm{m}^{3}$ para lotes com área superior a essa, de acordo com os cálculos apresentados no estudo de Drumond, Coelho e Moura (2011).

Tabela 1 - Parâmetros dos telhados verdes inseridos no SWMM

\begin{tabular}{|c|c|c|}
\hline \multirow{2}{*}{ Camada } & Parâmetro [unidade] & Valor \\
\hline \multirow{2}{*}{ Superfície } & Profundidade de armazenamento acima do nível do solo [mm] & 100 \\
\cline { 2 - 3 } & Rugosidade superficial [adimensional] & 0,035 \\
\cline { 2 - 3 } & Declividade superficial [\%] & 8,75 \\
\hline Solo & Espessura da camada [mm] & 100 \\
\hline Drenagem & Espessura da camada [mm] & 70 \\
\hline
\end{tabular}

Tabela 2: Parâmetros dos reservatórios de lote inseridos no SWMM

\begin{tabular}{|c|c|c|c|}
\hline Camada & Parâmetro [unidade] & $\begin{array}{l}\text { Valor } \mathrm{p} / \text { reserv. de } \\
1,08 \mathrm{~m}^{3}\end{array}$ & $\begin{array}{l}\text { Valor } \mathrm{p} / \text { reserv. de } \\
3,60 \mathrm{~m}^{3}\end{array}$ \\
\hline Armazenamento & Altura [mm] & 1140 & 1590 \\
\hline $\begin{array}{l}\text { Dreno } \\
\text { de fundo }\end{array}$ & $\begin{array}{l}\text { Coeficiente de descarga unitário, C } \\
\text { [adimensional] }\end{array}$ & 1,45 & 1,22 \\
\hline
\end{tabular}


Para cálculo do coeficiente de descarga unitário C utilizou-se a Eq. 1 (ROSSMAN, 2016):

$$
q=C(h)^{n}
$$

onde: $q$ = vazão de saída escoada pelo dreno, por área, em $[\mathrm{mm} / \mathrm{h}] ; \mathrm{C}=$ coeficiente de descarga unitário, adimensional; $\mathrm{h}$ = carga hidráulica sobre o dreno, em mm; $\mathrm{n}$ = expoente de descarga, igual a 0,5 considerando funcionamento como orifício, adimensional.

Nesse sentido, é necessário definir a vazão efluente desejada; no presente estudo foi adotada uma igual à vazão de pico efluente do lote considerando a situação de pré-urbanização. Essa vazão foi calculada por meio do método racional, de acordo com o que preconiza a Prefeitura de Belo Horizonte para os projetos de drenagem urbana (SUDECAP, 2004) e conforme a Eq. 2:

$$
Q=C_{e} x I
$$

onde: $\mathrm{Q}$ = vazão efluente do lote, em $\mathrm{mm} / \mathrm{h} ; \mathrm{C}_{\mathrm{e}}=$ coeficiente de escoamento superficial; $\mathrm{I}$ = intensidade da chuva de projeto, em $\mathrm{mm} / \mathrm{h}$.

Segundo Ramos (1998) apud Drumond, Coelho e Moura (2011), o coeficiente de escoamento superficial adotado em Belo Horizonte para solo em condição natural deve ser igual a 0,25. Quanto à intensidade da precipitação, a "Instrução técnica para elaboração de estudos e projetos de drenagem urbana do município de Belo Horizonte" (SUDECAP, 2004) recomenda o uso de valores de precipitação correspondentes a 10 anos de tempo de retorno (TR) e duração de 10 minutos. Esse valor corresponde a $195 \mathrm{~mm} / \mathrm{h}$, conforme a equação de chuvas intensas definida por Pinheiro e Naghettini (1998) para a Região Metropolitana de Belo Horizonte. Dessa forma, a vazão máxima efluente do lote, calculada pela Eq. 2, foi de $48,78 \mathrm{~mm} / \mathrm{h}$.
A partir dessa vazão e conhecendo-se a altura do reservatório foi possível calcular, com a Eq. 1, o valor do coeficiente de descarga unitário para os reservatórios de lote de $1,08 \mathrm{~m}^{3}$ e 3,60 $\mathrm{m}^{3}$, apresentados na Tabela 2.

Com relação à simulação, sua duração total foi de 36 horas, com passo de tempo de 30 segundos para os cálculos e os resultados sendo reportados a cada minuto. Os eventos chuvosos avaliados tiveram início junto com a simulação e foram discretizados também em intervalos de 1 minuto.

\subsection{Construção dos cenários com técnicas compensatórias}

Nessa etapa definiu-se a abrangência da implantação das técnicas compensatórias na área de estudo. Em outras palavras, definiu-se qual a porcentagem da área das sub-bacias seria tratada pelas técnicas compensatórias. Para tanto, foram construídos três cenários de análise com base na inspeção visual de imagens de satélite da área de estudo:

- Cenário C100: todas as edificações com telhados em telha cerâmica instalariam reservatórios de lote para captação de $100 \%$ da água da chuva que cai no telhado, e todas as edificações com telhados planos (inclinação inferior a $20^{\circ}$ ) e em material distinto de cerâmica instalariam telhados verdes em $100 \%$ da área do telhado;

- Cenário C50: 50\% das edificações com telhados em telha cerâmica instalariam reservatórios de lote para captação de $100 \%$ da água da chuva que cai no telhado, e $50 \%$ das edificações com telhados planos (inclinação inferior a $20^{\circ}$ ) e em material distinto de cerâmica instalariam telhados verdes em $100 \%$ da área do telhado;

- Cenário CO: corresponde à bacia em suas condições atuais e foi utilizado para comparação com os resultados encontrados nos cenários C100 e C50. 
Já o cálculo da área de telhados planos e inclinados em cada sub-bacia foi feito com o auxílio de imagens de satélite do dia 15 de maio de 2018 obtidas por meio do software Google Earth Pro (versão 7.3.2.5776, Google). Para cada sub-bacia, identificou-se uma área representativa em termos dos tipos de telhados existentes. Essa área representativa abrangeu ao menos $5 \%$ da área total da sub-bacia e foi utilizada para quantificação de (i) telhados inclinados com teIhas cerâmicas separados entre lotes maiores e menores que $360 \mathrm{~m}^{2} \mathrm{e}$; (ii) telhados planos. Os resultados obtidos para a área representativa foram extrapolados para toda a área da sub-bacia. Esses resultados podem ser observados na Tabela 3.

Tabela 3 - Áreas de telhados planos e inclinados para todas as sub-bacias.

\begin{tabular}{|c|c|c|c|c|}
\hline Id. da sub-bacia & Área da sub-bacia $\left(\mathrm{m}^{2}\right)$ & $\begin{array}{l}\text { Área total de telhados } \\
\text { inclinados - lote } \leq 360 \\
\qquad \mathbf{m}^{2}\left(\mathrm{~m}^{2}\right)\end{array}$ & $\begin{array}{l}\text { Área total de telhados } \\
\text { inclinados - lote }>360 \\
\qquad \mathbf{m}^{2}\left(\mathrm{~m}^{2}\right)\end{array}$ & $\begin{array}{l}\text { Área total de telhados } \\
\text { planos }\left(\mathbf{m}^{2}\right)\end{array}$ \\
\hline 1 & 202.500 & 2.935 & 5.994 & 34.407 \\
\hline 2 & 185.800 & 23.741 & - & 48.025 \\
\hline 3 & 201.600 & - & 8.690 & 35.757 \\
\hline 4 & 121.900 & - & 10.335 & 33.893 \\
\hline 5 & 637.100 & 49.459 & 88.933 & 107.794 \\
\hline 6 & 380.500 & - & - & 141.879 \\
\hline 7 & 219.300 & 7.131 & 11.853 & 24.281 \\
\hline 8 & 221.200 & - & 1.290 & 12.593 \\
\hline 9 & 545.700 & 24.011 & 44.975 & 126.007 \\
\hline 10 & 189.800 & - & - & 26.066 \\
\hline 11 & 3.255 .500 & - & 64.974 & 127.732 \\
\hline 12 & 1.256 .600 & 11.635 & 6.356 & 432.880 \\
\hline 13 & 642.100 & 13.008 & 107.404 & 55.702 \\
\hline 14 & 1.018 .600 & 143.892 & 77.067 & 152.553 \\
\hline 15 & 959.700 & 47.686 & 130.963 & 153.274 \\
\hline Total & 10.037 .900 & 323.499 & 558.834 & 1.512 .844 \\
\hline
\end{tabular}

A área total de telhados que podem ser tratados por técnicas compensatórias corresponde a $33 \%$ da área impermeável da bacia. Desse valor, 63\% será tratado por telhados verdes e $37 \%$ por reservatórios de lote, no cenário C100.

Por fim, foi feita a definição das chuvas de projeto a serem modeladas, a partir da análise do cenário $\mathrm{C} 0$. Para esse cenário, foram simuladas chuvas considerando os tempos de retorno de 10 e 50 anos, com durações entre 10 minutos e 24 horas. Os valores das intensidades da precipitação foram calculados segundo o trabalho de Pinheiro e Naghettini (1998) e, assim como feito por esses autores para Belo Horizonte, discreti- zados segundo a curva de $50 \%$ de probabilidade do método de Huff.

Os hietogramas de projeto obtidos foram usados para a simulação do cenário CO no SWMM. A partir dessa simulação foi identificada a chuva de duração crítica para cada tempo de retorno (10 e 50 anos), cujas intensidades estão apresentadas na Tabela 4. A chuva de duração crítica foi aquela que produziu a maior vazão de pico no exutório da bacia no cenário CO (VERSINI et. al., 2015). Além disso, incluiu-se também a chuva de duração de 10 minutos por ser essa a recomendada pela SUDECAP (2004) em projetos de dispositivos de drenagem urbana. 
Tabela 4 - Intensidades de precipitação definidas para modelagem a partir do cenário $\mathrm{CO}$.

\begin{tabular}{|c|c|c|}
\hline \multirow{2}{*}{ Duração } & \multicolumn{2}{|c|}{ Intensidade $(\mathbf{m m} / \mathbf{h})$} \\
\cline { 2 - 3 } & TR $=\mathbf{1 0}$ anos & TR $=\mathbf{5 0}$ anos \\
\hline 10 min & 195,12 & 244,72 \\
\hline $1 \mathrm{~h}$ & 55,74 & - \\
\hline $2 \mathrm{~h}$ & - & 42,87 \\
\hline
\end{tabular}

\section{RESULTADOS}

\subsection{Avaliação do desempenho das técnicas compensatórias}

A título de ilustração, as Figs. 3 e 4 apresentam o balanço hídrico representativo dos telhados verdes da sub-bacia 1 para o tempo de retorno de 50 anos e duração de, respectivamente, 10 minutos e 2 horas. Resultados similares foram obtidos para as demais sub-bacias e demais cenários de simulação.

Em nenhum dos cenários simulados ocorreu geração de escoamento superficial sobre os telhados verdes. A vazão máxima drenada por eles foi de $10,92 \mathrm{~mm} / \mathrm{h}$ em todos os cenários. Isso significa liberar uma vazão correspondente a $4,5 \%$ da precipitação de maior intensidade (10 minutos para TR de 50 anos) e a $25,5 \%$ da chuva de menor intensidade ( 2 horas e TR de 50 anos). A Tabela 5 apresenta a altura de água retida pelos telhados verdes ao final da simulação.
Tabela 5 - Altura de água retida nos telhados verdes nos cenários C100 e C50 ao final da simulação.

\begin{tabular}{|c|c|c|c|}
\hline \multicolumn{4}{|c|}{ Altura retida $\mathbf{( m m})$} \\
\hline TR 10 & TR 10 & TR 50 & TR 50 \\
\hline $\mathbf{1 0}$ min & $\mathbf{1} \mathbf{h}$ & $\mathbf{1 0} \mathbf{~ m i n}$ & $\mathbf{2} \mathbf{~ h}$ \\
\hline 32,7 & 33,0 & 32,8 & 33,2 \\
\hline
\end{tabular}

Conclui-se que o dimensionamento dos telhados verdes garantiu volume de armazenamento suficiente para as precipitações de projeto simuladas, possibilitando o amortecimento das vazões geradas nos lotes.

A Fig. 5 apresenta o balanço hídrico representativo dos reservatórios de lote com volume de $3,6 \mathrm{~m}^{3}$ na sub-bacia 1. Resultados similares foram obtidos para os reservatórios de volume $1,08 \mathrm{~m}^{3}$, nas demais sub-bacias e demais cenários de simulação.

Para todas as precipitações de projeto avaliadas, em ambos cenários $\mathrm{C} 100$ e C50, ocorreu extravasamento dos reservatórios de lote, os quais pouco tempo após o início do evento chuvoso atingiram sua capacidade máxima de armazenamento. A partir do momento em que o extravasamento ocorre, toda a vazão de entrada transforma-se em escoamento superficial. Dessa forma, percebe-se que os reservatórios de lote não apresentaram volume suficiente para garantir o amortecimento das vazões geradas nos lotes.

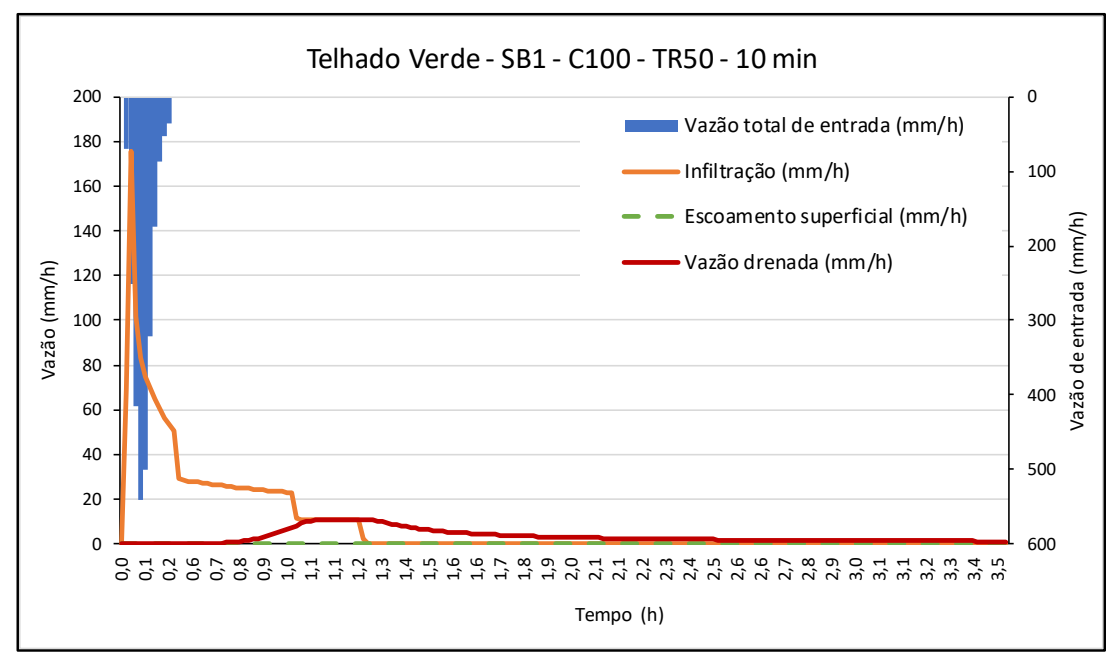

Figura 3 - Hidrograma representativo dos telhados verdes na sub-bacia 1, considerando cenário C100 e precipitação com tempo de retorno de 50 anos e duração de 10 minutos. 


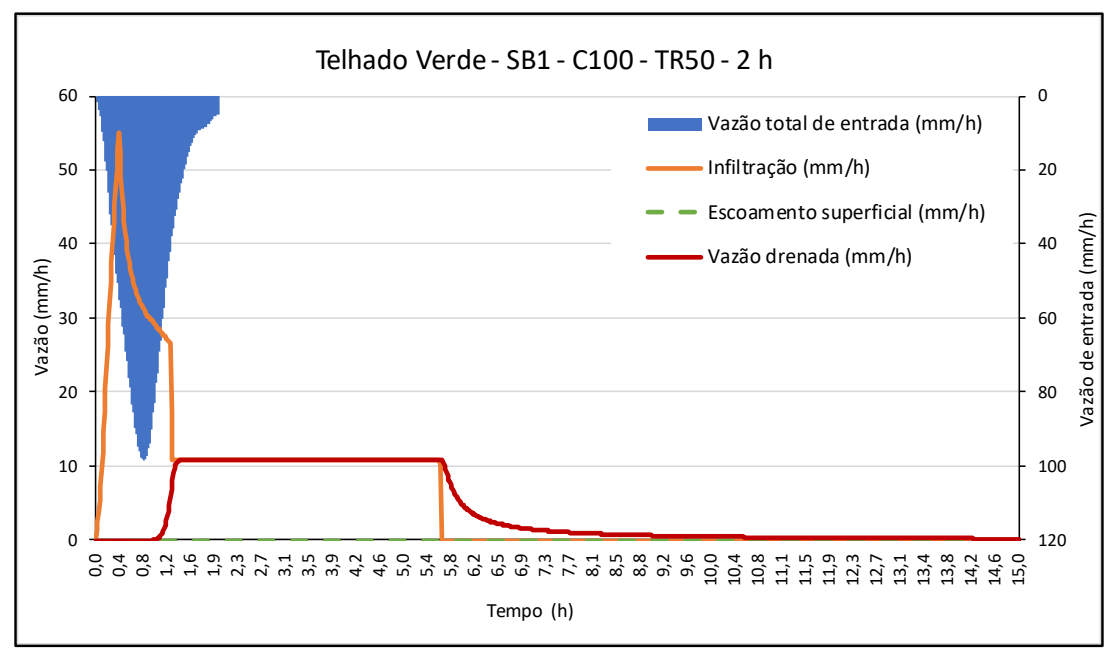

Figura 4 - Hidrograma representativo dos telhados verdes na sub-bacia 1, considerando cenário C100 e precipitação com tempo de retorno de 50 anos e duração de 2 horas.

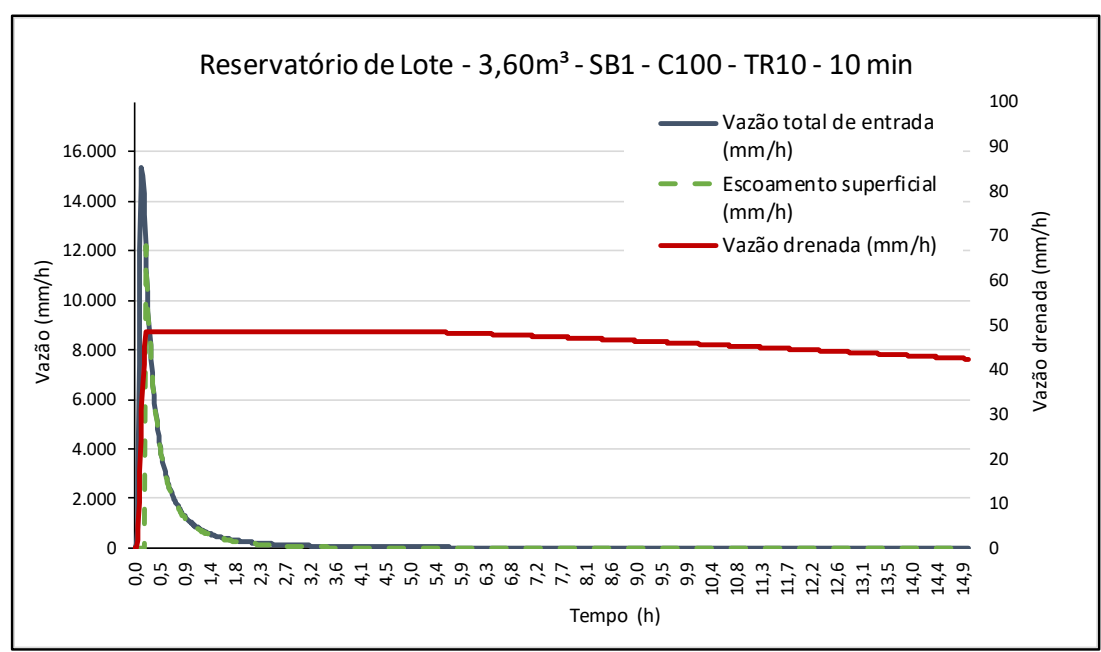

Figura 5 - Hidrograma representativo dos reservatórios de lote de 3,60 $\mathrm{m}^{3}$ na sub-bacia 1 considerando cenário C100 e precipitação com tempo de retorno de 10 anos e duração de 10 minutos.

\subsection{Impacto das técnicas compensatórias no escoamento superficial na bacia}

A Tabela 6 apresenta os valores de escoamento superficial total na bacia do Córrego Engenho Nogueira para todos os cenários e precipitações avaliados. Nota-se que em todos eles houve redução na altura do escoamento superficial de $8,9 \%$ a 22,3\% em relação ao cenário de referência $\mathrm{CO}$. Isso se deve à retenção da precipitação nos telhados verdes e ao armazenamento da pre- cipitação nos reservatórios de lote, os quais ao final da simulação ainda armazenam uma lâmina d'água. Essas técnicas evitam que parte da chuva que cai sobre os telhados se transforme direta e imediatamente em escoamento superficial. Os telhados verdes retêm parte da chuva em sua vegetação e solo, enquanto os reservatórios de lote captam e armazenam parte da precipitação, liberando-a posteriormente para o sistema de drenagem (caso não haja extravasamento). 
Tabela 6 - Escoamento superficial na bacia do Córrego Engenho Nogueira. $\Delta_{\mathrm{C} 0-\mathrm{C50}}$ e $\Delta_{\mathrm{C} 0-\mathrm{C} 100}$ representam a variação percentual do escoamento superficial, respectivamente, nos cenários C50 e C100 em relação ao cenário

\begin{tabular}{|c|c|c|c|c|c|c|}
\hline \multicolumn{1}{|c|}{} & $\begin{array}{c}\text { Precipitação } \\
\text { (mm) }\end{array}$ & C0 & C50 & $\boldsymbol{\Delta}_{\text {co-c50 }}$ & Escoamento superficial total na bacia (mm) \\
\hline TR 10 - 10min & 32,5 & 25,61 & 22,75 & $11,2 \%$ & 19,91 \\
\hline TR 10 - 1h & 55,7 & 47,47 & 42,86 & $9,7 \%$ & 38,26 \\
\hline TR 50 - 10min & 40,8 & 32,57 & 29,08 & $10,7 \%$ & $25,3 \%$ \\
\hline TR 50 - 2h & 85,7 & 77,37 & 70,49 & $8,9 \%$ & $21,4 \%$ \\
\hline
\end{tabular}

\subsection{Impacto das técnicas compensatórias na} vazão e no tempo de pico no exutório da bacia

Os resultados encontrados no exutório da bacia para todos os cenários e precipitações avaliados estão resumidos na Tabela 7, e a Fig. 6 representa o hidrograma no exutório da bacia para a precipitação de duração de $1 \mathrm{~h}$ e tempo de retorno de 10 anos.

Ao avaliar os resultados no exutório da bacia nota-se que, para o cenário $\mathrm{C} 100$, as reduções na vazão de pico variam entre $0,1 \%$ (para a precipitação de $2 \mathrm{~h}$ e tempo de retorno de 50 anos) e 11,6\% (para a precipitação de 10 min e tempo de retorno de 10 anos), em comparação com o cenário base (C0). Já para o cenário $\mathrm{C} 50$, as variações na vazão de pico ocorrem entre $1,1 \%$ de aumento (precipitação de 10 min e tempo de re- torno de 50 anos) e 4,1\% de redução (precipitação de 10 min e tempo de retorno de 10 anos), valores inferiores ao cenário $\mathrm{C} 100$. Essa situação é coerente, uma vez que, no cenário $\mathrm{C} 100$, a área da bacia tratada por meio de técnicas compensatórias é maior do que no cenário $\mathrm{C} 50$, o que reduz o escoamento superficial e a vazão de pico no exutório.

Destaca-se, entretanto, que para as precipitações de tempo de retorno de 50 anos no cenário C50 houve um pequeno aumento da vazão de pico quando comparado ao cenário CO. Já com relação aos tempos de pico não houve alteração significativa entre os cenários avaliados, de forma que os picos de vazão no exutório aconteceram praticamente no mesmo instante (variações máximas de 4 minutos).

Tabela 7 - Vazão de pico e tempo de pico dos cenários C0, C50 e C100 no ponto exutório da bacia do Engenho Nogueira. $\Delta \mathrm{Q}_{\max } \mathrm{CO}$-C50 e $\Delta \mathrm{Q}_{\max } \mathrm{CO}$-C100 representam a variação percentual do escoamento superficial, respectivamente, nos cenários $\mathrm{C} 50$ e $\mathrm{C} 100$ em relação ao cenário $\mathrm{CO}$.

\begin{tabular}{|c|c|c|c|c|c|c|c|c|}
\hline & \multicolumn{2}{|c|}{ Co } & \multicolumn{3}{|c|}{ C50 } & \multicolumn{3}{|c|}{ C100 } \\
\hline & $\begin{array}{l}\text { Qmax } \\
\left(\mathrm{m}^{3} / \mathrm{s}\right)\end{array}$ & $\begin{array}{c}T_{\text {pico }} \\
(\mathrm{min})\end{array}$ & $\begin{array}{l}Q_{\max } \\
\left(m^{3} / s\right)\end{array}$ & $\begin{array}{c}\Delta Q_{\max } \\
\text { C0-C50 }\end{array}$ & $\begin{array}{c}T_{\text {pico }} \\
\text { (min) }\end{array}$ & $\begin{array}{c}Q_{\max } \\
\left(\mathrm{m}^{3} / \mathrm{s}\right)\end{array}$ & $\begin{array}{c}\Delta \mathbf{Q}_{\max } \\
\mathrm{C} 0-\mathrm{C} 100\end{array}$ & $\begin{array}{c}T_{\text {pico }} \\
(\min )\end{array}$ \\
\hline TR10 - $10 \mathrm{~min}$ & 40,61 & 14 & 38,94 & $4,1 \%$ & 14 & 35,88 & $11,6 \%$ & 15 \\
\hline TR10-1 h & 52,33 & 43 & 50,36 & $3,8 \%$ & 39 & 48,40 & $7,5 \%$ & 39 \\
\hline TR50 - $10 \mathrm{~min}$ & 48,70 & 13 & 49,25 & $-1,1 \%$ & 12 & 43,45 & $10,8 \%$ & 14 \\
\hline TR50-2h & 55,85 & 59 & 56,37 & $-0,9 \%$ & 61 & 55,79 & $0,1 \%$ & 63 \\
\hline
\end{tabular}




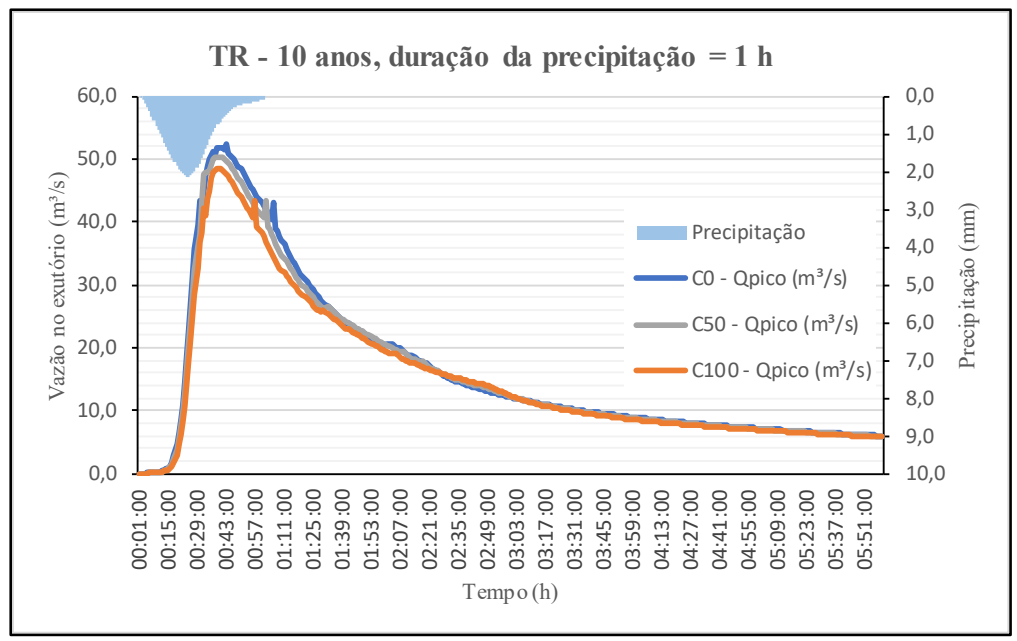

Figura 6 - Hidrograma no ponto exutório da bacia do Engenho Nogueira, considerando TR de 10 anos e precipitação de 1 hora.

A explicação para esses dois fenômenos pode estar relacionada ao desempenho das técnicas compensatórias, mais especificamente aos reservatórios de lote. Conforme explicado no item 3.1, esses reservatórios não estão atuando efetivamente para a redução e o amortecimento das vazões escoadas. Mas eles podem estar contribuindo para que mais vazão chegue ao exutório simultaneamente a partir do atraso nos hidrogramas de algumas sub-bacias, causando o aumento na vazão de pico verificado no cenário C50.

\section{DISCUSSÃO}

\subsection{Efetividade das técnicas compensatórias na bacia em estudo}

Em relação à redução do escoamento superficial na bacia, o trabalho de Versini et. al. (2015), que simulou a implantação de telhados verdes em uma bacia urbana em Paris, encontrou valores similares àqueles aqui reportados (entre 9,7\% e $22,3 \%$ ). No estudo francês, cerca de $29 \%$ da área total da bacia foi coberta apenas por telhados verdes, o que reduziu o escoamento superficial em $14 \%$.
Em relação à redução da vazão de pico no exutório da bacia, os valores encontrados neste estudo foram inferiores a outros estudos similares realizados. Fernandes (2018) encontrou reduções de $65 \%$ a $70 \%$ na vazão de pico da bacia Córrego Flor d'água, próxima à do Engenho Nogueira, simulando a implantação de telhados verdes, reservatórios de lote e jardins de chuva. A discrepância nos resultados encontrados pode ser justificada pelo uso dos jardins de chuva na simulação de Fernandes (2018), o que possibilitaria o tratamento de uma maior área da bacia.

Já Rosa (2017) obteve reduções de 60\% (no meIhor cenário) e 30\% (em um cenário mediano) na vazão de pico do exutório, ao avaliar a implantação de telhados verdes, reservatórios de lote, trincheiras de infiltração, pavimentos permeáveis e desconexão de telhados na bacia do Córrego Leitão, em Belo Horizonte. Nesse caso, a diferença com relação aos resultados da bacia do Engenho Nogueira pode estar relacionada à maior variedade de técnicas utilizadas na bacia do Leitão (não apenas de controle na fonte), bem como à porcentagem da bacia tratada por técnicas compensatórias: Rosa (2017) tratou cerca de $69 \%$ da área impermeável, enquanto na bacia 
do Engenho Nogueira tratou-se cerca de 33\% no melhor cenário (C100).

É válido notar ainda que em alguns cenários simulados no presente estudo as reduções nas vazões de pico decorrentes da implantação de técnicas compensatórias na bacia são de pequena magnitude (inferior a 5\%) frente às incertezas que são inerentes ao processo de modelagem.

Comparando as alterações na vazão de pico no exutório e no escoamento superficial da bacia percebe-se que a redução do segundo é mais expressiva que a do primeiro. Isso pode ser explicado pela existência da bacia de detenção na porção média da bacia do Engenho Nogueira: ela amortece as vazões provenientes da porção de montante em todos os cenários, o que pode minimizar o impacto das técnicas compensatórias na redução da vazão de pico no exutório para os cenários C50 e C100. Outra possibilidade seria a operação insatisfatória dos reservatórios de lote, que contribuem pouco ou nada para a redução da vazão de pico ao fazer com que múltiplos hidrogramas cheguem ao exutório simultaneamente. Entretanto, considerando a duração da simulação realizada nesse estudo, eles contribuem para a redução do escoamento superficial.

\subsection{Implementação de técnicas compensatórias no município de Belo Horizonte}

Em uma revisão bibliográfica sobre o desempenho e a implementação de técnicas compensatórias, Eckart, McPhee e Bolisetti (2017) destacaram o fato de que vários estudos consideram que a falta de políticas públicas visando à regulação das técnicas compensatórias é uma limitação para sua disseminação.

Em Belo Horizonte, a política municipal de saneamento foi instituída a partir da Lei 8260/01 (BELO HORIZONTE, 2001) que, em seu texto, valoriza a integração dos canais fluviais à paisagem urbana, bem como a minimização de inter- venções urbanas que levem à expansão de áreas impermeáveis. Essas observações se mostram favoráveis à implantação de técnicas compensatórias no âmbito da drenagem urbana. Entretanto, não existem instrumentos complementares à lei detalhando como a transição de abordagens tradicionais para abordagens alternativas poderia ser implementada.

A iniciativa municipal que se mostrou mais favorável às abordagens compensatórias em drenagem urbana foi o Programa Drenurbs, cujo objetivo principal é reverter a tendência de canalização dos rios de Belo Horizonte (BELO HORIZONTE, 2016). Apesar de focar mais especificamente na revitalização dos cursos d'água da cidade, existe o reconhecimento por parte do Programa de que "medidas que visem o aumento da permeabilidade do solo, da retenção e do retardamento dos escoamentos superficiais podem aliviar as vazões afluentes aos fundos de vale e calhas dos córregos". Ou seja, a importância da adoção de técnicas compensatórias para a suficiência e bom funcionamento do sistema de drenagem urbana é reconhecida, mas não é explicitada.

A única legislação de Belo Horizonte que efetivamente menciona uma das técnicas compensatórias (os reservatórios de lote) é a Lei de Parcelamento, Ocupação e Uso do Solo - LPOUS (BELO HORIZONTE, 1996). Nessa lei, os reservatórios são indicados como uma possibilidade para aquelas edificações que impermeabilizem $100 \%$ do lote: para compensar o desrespeito à taxa mínima de permeabilidade, o dono do lote tem a opção de construir uma "caixa de captação e drenagem que retarde o lançamento das águas pluviais”, capaz de reter 30 litros de água por metro quadrado impermeabilizado acima do permitido.

Avaliando os resultados desse trabalho e do estudo realizado por Drumond, Coelho e Moura 
(2011), conclui-se que o volume de reservatório de lote especificado pela legislação municipal não é suficiente para armazenar e retardar o lançamento das águas de chuva na rede de drenagem urbana.

Já em relação ao cenário legislativo municipal sobre técnicas compensatórias, é possível perceber que Belo Horizonte praticamente não incentiva sua implantação, não apresenta os tipos de técnicas compensatórias existentes ao contribuinte e, portanto, não faz muitas exigências com relação a soluções complementares/alternativas de drenagem. Portanto, há uma oportunidade de evolução da legislação de Belo Horizonte em direção ao maior incentivo de aplicação de técnicas compensatórias de drenagem urbana.

\section{CONCLUSÃO E RECOMENDAÇÕES}

A partir da análise dos resultados da modelagem de telhados verdes e reservatórios de lote na bacia do córrego Engenho Nogueira foi possível perceber que as técnicas compensatórias implantadas contribuíram para a redução de até $11,6 \%$ da vazão de pico no exutório da bacia, bem como para a redução de até $22,3 \%$ no escoamento superficial gerado. Esses dois valores correspondem a chuvas com tempo de retorno igual a 10 anos e duração de 10 minutos. Para chuvas mais intensas, que apresentam maior potencial causador de enchentes, o escoamento superficial da bacia foi reduzido entre $8,9 \%$ e 19,4\%. Entretanto, a vazão de pico no exutório praticamente não apresentou redução para chuvas com TR de 50 anos e duração de 2 horas.

A pequena redução nas vazões de pico no exutório está relacionada ao pequeno volume de armazenamento dos reservatórios de lote, uma vez que ocorreu extravasamento da maior parte desse volume. Nesse sentido, conclui-se que os volumes de reservatório determinados pela legislação municipal devem ser revisados e au- mentados para permitir o controle do escoamento superficial na fonte. Seria interessante também que a legislação exigisse a instalação de reservatórios de lote em mais situações além da prevista atualmente.

Outra possibilidade para justificar os resultados apresentados no exutório da bacia seria a porcentagem da área impermeável tratada: no meIhor cenário, foi tratada 33\% da área impermeável da bacia com reservatórios de lote e telhados verdes. Diante disso, seria interessante realizar novo estudo, considerando volumes de reservatório maiores e aumentando a porcentagem de área impermeável tratada da bacia, inclusive acrescentando outras técnicas compensatórias.

É interessante observar que a aplicação de técnicas de controle na fonte realmente apresenta potencial para reduzir inundações urbanas, sem a necessidade de obras no sistema de drenagem existente. Mesmo com os pontos de melhoria apontados neste trabalho, ainda foi possível identificar benefícios para a bacia analisada, especialmente em termos do escoamento superficial gerado.

Para continuidade e aprofundamento desse estudo, além dos pontos já mencionados recomenda-se a utilização de ferramentas computacionais em um ambiente georreferenciado para identificação mais acurada das áreas de telhados planos e inclinados na bacia. Também sugere-se realizar a simulação utilizando registros de eventos de chuva reais na região.

Destaca-se, por fim, a importância de se estudar e entender a aplicação de técnicas compensatórias considerando todo o contexto do local de implantação (características da bacia hidrográfica, precipitação, legislação etc.), pois especificidades locais podem interferir nos resultados de forma imprevista. 


\section{CONTRIBUIÇÃO DOS AUTORES}

Todos os autores contribuíram de forma igualitária.

\section{REFERÊNCIAS}

BELO HORIZONTE. Lei no 7.166, de 27 de agosto de 1996. Estabelece normas e condições para parcelamento, ocupação e uso do solo urbano no município. Belo Horizonte, MG, ago 1996. Disponível em: < https://www.cmbh.mg.gov.br/atividade-legislativa/ pesquisar-legislacao/lei/7166/1996>. Acesso em: 06 mar. 2019.

BELO HORIZONTE. Lei $n^{\circ}$ 8.260, de 3 de dezembro de 2001. Institui a política municipal de saneamento e dá outras providências. Belo Horizonte, MG, dez 2001. Disponível em: <https://cm-belo-horizonte.jusbrasil.com.br/legislacao/236832/ lei-8260-01?print=true>. Acesso em: 13 fev. 2019.

BELO HORIZONTE. Plano Municipal de Saneamento de Belo Horizonte - PMS 2016/2019. Prefeitura de Belo Horizonte, 2016. 203 p. Disponível em: <https://prefeitura.pbh.gov.br/obras-e-infraestrutura/informacoes/publicacoes/plano-de-saneamento>. Acesso em: 13 fev. 2019.

COBRADE, Codificação e classificação Brasileira de Desastres. 2012. Disponível em: < http://www.integracao.gov.br/documents/3958478/0/Anexo+V+-+Cobrade_com+simbologia.pdf/ d7d8bb0b-07f3-4572-a6ca-738daa95feb0>. Acesso em: 02 fev. 2019.

DRUMOND, P. P.; COELHO, M. M. L. P.; MOURA, P. M. Análise do volume de reservação de águas pluviais em lotes: comparação do caso de Belo Horizonte com outras cidades brasileiras. In: XIX SIMPÓSIO BRASILEIRO DE RECURSOS HÍDRICOS, 2011, Maceió. Associação Brasileira de Recursos Hídricos. Anais... Disponível em: < https://www.abrh.org.br/SGCv3/index.php?PUB=3\&ID=81\&SUMARIO=1021\&ST=analise_do_volume_de_reservacao_de_aguas_ pluviais_em_lotes_comparacao_do_caso_de_belo_horizonte_ com_outras_cidades_brasileiras>. Acesso em: 07 abr. 2019.

ECKART, K.; MCPHEE, Z.; BOLISETTI, T. Performance and implementation of low impact development - a review. Science of the Total Environment, 607-608, p. 413-432, 2017. https://doi.org/10.1016/j.scitotenv.2017.06.254

FERNANDES, C. Y. Inserção de trama verde e azul em ocupações urbanas consolidadas orientada pela participação social. 2018. 116 f. Dissertação (Mestradoem Saneamento, Meio Ambiente e Recursos Hídricos), Escola de Engenharia, Universidade Federal de Minas Gerais, Belo Horizonte, 2018.

GARCIA, J. I. B.; PAIVA, E. M. C. D. Monitoramento Hidrológico e Modelagem da Drenagem Urbana da Bacia do Arroio Cancela - RS. Revista Brasileira de Recursos Hídricos, [s. L.], v. 11, n. 4, p.99108, dez. 2006. Trimestral. https://doi.org/10.21168/rbrh.v11n4. p99-108
LUCAS, T. P. B.; AUGUSTO, P.; REIS, S.; ROCHA, S. C. Impactos Hidrometeóricos em Belo Horizonte - MG. Revista Brasileira de Climatologia, [s. L.], v. 16, p.7-28, jan./jul. 2015. Semestral. http:// dx.doi.org/10.5380/abclima.v16io.37051

NRCS - NATURAL RESOURCES CONSERVATION SERVICE. United States Department of Agriculture. Estimation of direct runoff from storm rainfall. Part 630: hydrology. In: U.S. DEPARTMENT OF AGRICULTURE - USDA. National engineering handbook. Washington: USDA, 2004. cap. 10.

PBH - Prefeitura de Belo Horizonte. Arquivo de zoneamento de Belo Horizonte. 2018. Disponível em: <https://prefeitura.pbh. gov.br/politica-urbana/planejamento-urbano/base-de-dados/ mapas-e-estatisticas>. Acesso em: 06 mar. 2019.

PBH - Prefeitura de Belo Horizonte. Arquivo de bacias urbanas de Belo Horizonte. 2018. Disponível em: <https://prefeitura.pbh. gov.br/estatisticas-e-indicadores/downloads>. Acesso em: 06 mar. 2019.

PINHEIRO, M. M. G.; NAGUETTINI, M. C. Análise Regional de Frequência e Distribuição Temporal das Tempestades na Região Metropolitana de Belo Horizonte. Revista Brasileira de Recursos Hídricos, v. 3, n. 4, p. 73-88, Out/Dez 1998. https://doi. org/10.21168/rbrh.v3n4.p73-88

RAMOS, M. H. D. Drenagem urbana: aspectos urbanísticos, legais e metodológicos em Belo Horizonte. 1998. 103f. Dissertação (Mestrado em Saneamento, Meio Ambiente e Recursos Hídricos) Escola de Engenharia. Universidade Federal de Minas Gerais.

ReCESA - Rede Nacional de Capacitação e Extensão Tecnológica em Saneamento Ambiental. Águas Pluviais: Técnicas Compensatórias para o Controle de Cheias Urbanas - guia do profissional em treinamento: nível 2 e 3. Ministério das Cidades. Secretaria Nacional de Saneamento Ambiental (Org.). Belo Horizonte, 2007. 52 p. Disponível em: <http://nucase.desa.ufmg.br/wp-content/ uploads/2013/08/APU-TCCU.2-e-3.pdf>. Acesso em: 07 fev. 2019.

ROSA, D. W. B. Resposta hidrológica de uma bacia hidrográfica urbana à implantação de técnicas compensatórias de drenagem urbana - Bacia do Córrego do Leitão, Belo Horizonte, Minas Gerais. 2017. 218 f. Dissertação (Mestrado em Saneamento, Meio Ambiente e Recursos Hídricos), Escola de Engenharia, Universidade Federal de Minas Gerais, Belo Horizonte, 2017.

ROSSMAN, L. A. Storm Water Management Model - User's Manual: Version 5.0. Cincinnati, EUA: U.S. Environmental Protection Agency, 2015. 352 p. Disponível em: <https://www.epa.gov/sites/ production/files/2019-02/documents/epaswmm5_1_manual_ master_8-2-15.pdf>. Acesso em: 25 fev. 2019.

ROSSMAN, L. A. Storm Water Management Model Reference Manual - Volume III - Water Quality. Cincinnati, EUA: U.S. Environmental Protection Agency, 2016. 161 p. Disponível em: < https://nepis.epa.gov/Exe/ZyPDF.cgi/P100P2NY.PDF?Dockey=P100P2NY.PDF>. Acesso em: 27 abr. 2019. 
SILVA, T. F. G. et al. Modelagem da Lagoa da Pampulha: uma ferramenta para avaliar o impacto da bacia hidrográfica na dinâmica do fitoplâncton. Engenharia Sanitária e Ambiental, [s.l.], v. 21, n. 1, p.95-108, mar. 2016. FapUNIFESP (SciELO). http://dx.doi. org/10.1590/s1413-41520201600100125692.

SILVA, T. F. G. et al. Impact of Urban Stormwater Runoff on Cyanobacteria Dynamics in A Tropical Urban Lake. Water, [s.l.], v. 11, n. 5, p.946-976, 5 mai. 2019. MDPI AG. http://dx.doi.org/10.3390/ w11050946.

SIQUEIRA, R. C.; MOURA, P. M.; SILVA, T. F. G. Methodology for the construction of an urban flood hazard chart. Revista Brasileira de Recursos Hídricos - RBRH, [s.l.], v. 24, 20 mar. 2019. FapUNIFESP (SciELO). http://dx.doi.org/10.1590/2318-0331.241920180125.

SUDECAP. Instrução técnica para elaboração de estudos e projetos de drenagem urbana do município de Belo Horizonte. Superintendência de Desenvolvimento da Capital, 2004. 53p.

TASSI, R. Efeito dos microrreservatórios de lote sobre a macrodrenagem urbana. 2002. 156 f. Dissertação (Mestrado em Engenharia de Recursos Hídricos e Saneamento Ambiental), Instituto de Pesquisas Hidráulicas, Universidade Federal do Rio Grande do Sul, Porto Alegre, 2002.

TOMAZ, P. BMPs - Best Management Practices. 2009. 185 p. Livro eletrônico. Disponível em: <http://www.pliniotomaz.com.br/ downloads/livro01v02bmps.pdf>. Acesso em: 08 abr. 2019.

TUCCI, C. E. M. Inundações Urbanas. Material disponível na página do Ministério Público Federal como parte do curso "Gestão do Território e Manejo Integrado das Águas Urbanas". Disponível em: <http://www.mpf.mp.br/atuacao-tematica/ccr4/importacao/institucional/grupos-de-trabalho/encerrados/residuos/ documentos-diversos/outros_documentos_tecnicos/curso-gestao-do-terrimorio-e-manejo-integrado-das-aguas-urbanas/ drenagem1.PDF>. Acesso em: 18 dez. 2018.

VERSINI, P.; JOUVE, P.; RAMIER, D.; BeRTHIER, E.; GOUVELlO, $B$. Use of green roofs to solve storm water issues at the basin scale - Study in the Hauts-de-Seine County (France). Urban Water Journal, v. 13, n. 4, p.372-381, 7 jan. 2015. https://doi. org/10.1080/1573062X.2014.993993 